\title{
Is Hydrogen Breath Test with Lactulose Feasible for Measuring Gastrocecal Transit in Critically Ill Children? Pilot Study about Modification of the Technique
}

\author{
J. López, ${ }^{1}$ C. Sánchez, ${ }^{2}$ S. N. Fernández, ${ }^{1}$ R. González, ${ }^{1}$ M. J. Solana, ${ }^{1}$ J. Urbano, ${ }^{1}$ \\ M. Tolín, ${ }^{2}$ and J. López-Herce ${ }^{1}$ \\ ${ }^{1}$ Pediatric Intensive Care Department, Gregorio Marañón General University Hospital, School of Medicine, \\ Complutense University of Madrid, Gregorio Marañon Health Research Institute, Mother-Child Health and \\ Development Network (Red SAMID) of Carlos III Health Institute, Spain \\ ${ }^{2}$ Gastroenterology Unit, Gregorio Marañón General University Hospital, Complutense University of Madrid, Spain
}

Correspondence should be addressed to J. López; dr_pyta@yahoo.es and J. López-Herce; pielvi@hotmail.com

Received 2 September 2016; Revised 18 December 2016; Accepted 28 December 2016; Published 26 January 2017

Academic Editor: Toshimi Chiba

Copyright ( 2017 J. López et al. This is an open access article distributed under the Creative Commons Attribution License, which permits unrestricted use, distribution, and reproduction in any medium, provided the original work is properly cited.

\begin{abstract}
Introduction. Gastrocecal transit time (GCTT) can be measured by exhaled hydrogen after lactulose intake (lactulose-e $\mathrm{H}_{2}$ test). The objectives were to assess whether it is possible to carry out this test in critically ill children with and without mechanical ventilation (MV) and to analyze whether the results are consistent with clinical findings. Methods. Patients admitted to the Pediatric Intensive Care Unit (PICU) for more than 3 days were included. Those with gastrointestinal disease prior to admission were excluded. A modified technique to obtain $\mathrm{eH}_{2}$ from the ventilator tubes was performed. Results. Sixteen patients (37.5\% boys) with a median age of 19 (5-86.5) months were included. Five patients (31.2\%) were breathing spontaneously but lactulose-e $\mathrm{H}_{2}$ test could not be performed while it could be performed successfully in the 11 patients with MV. Seven patients (63.3\%) did not show an $\mathrm{eH}_{2}$ peak. The other 4 showed a median time of $130 \mathrm{~min}(78.7-278.7 \mathrm{~min})$ from lactulose intake to a $10 \mathrm{ppm} \mathrm{eH}_{2}$ peak. Children with an $\mathrm{eH}_{2}$ peak had intestinal movements earlier [6.5 (1.5-38.5) versus 44 (24-72) hours $\left.p=0.545\right]$. Conclusion. Although the designed adaption is useful for collecting breath samples, lactulose- $\mathrm{eH}_{2}$ test may not be useful for measuring GCTT in critically ill children.
\end{abstract}

\section{Introduction}

Critically ill patients, both adults and children, have a high incidence of gastrointestinal motility disorders. These disorders involve an increased risk of complications: gastrointestinal (nausea, vomiting, diarrhea, or constipation), nutritional (interruptions of enteral nutrition), and nongastrointestinal (increased risk of pulmonary aspiration) $[1,2]$.

The pathogenesis of gastrointestinal motility disorders in critically ill patients is related to inflammatory processes, sepsis, surgery, intracranial hypertension, hyperglycemia, electrolyte disturbances, and the use of different drugs such as inotropes or opioids $[1,3-6]$.

Motility disturbances can affect any segment of the digestive tract: the esophagus with an increased risk of gastroesophageal reflux; the stomach causing impaired gastric emptying; the small intestine causing changes in motility patterns and poor tolerance of enteral nutrition; or the colon, with an increased prevalence of constipation [7-9].

Numerous diagnostic methods have been developed for assessing digestive tract motility in the last few decades. However, most of them cannot be used in critically ill patients due to their clinical condition, mechanical ventilation, inability to manage specific substrates with standardized preparations, or difficulties to move patients to external radiology or nuclear medicine units [10].

The measurement of exhaled hydrogen after the administration of lactulose (lactulose- $\mathrm{eH}_{2}$ test) has been accepted for measuring gastrocecal transit time (GCTT) in both adults and children [11-13]. Different lactulose- $\mathrm{eH}_{2}$ test methods in noncooperating patients have been well described and they 
have been used routinely by pediatric gastroenterologists [1316].

Slow GCTT has been correlated with alterations in gut motility and gastrointestinal complications such as constipation or poor tolerance of enteral nutrition [11]. The main advantages of this test are that it is easy to perform, it is noninvasive and is of low cost, it can be performed at the patients' bedside, and it offers quick results. All these features facilitate its use in critically ill patients.

There are no validated methods for measuring GCTT in critically ill children. Nor are there any studies examining the ability of $\mathrm{eH}_{2}$-lactulose test to measure GCTT in critical pediatric patients.

The objectives of this pilot study were, first, to assess whether it is possible to carry out the lactulose- $\mathrm{eH}_{2}$ test in critically ill children with both spontaneous breathing and invasive mechanical ventilation. The second objective was to analyze whether the lactulose- $\mathrm{eH}_{2}$ test is able to measure GCTT in critical ill children and whether the results are consistent with clinical findings.

\section{Methods}

A prospective observational study was performed in the Pediatric Intensive Care Unit (PICU) of a university children's hospital. The PICU is an 11-bed mixed medical and surgical unit with around 400 admissions per year of children between 1 month and 16 years of age. The study was approved by the Local Institutional Review Body. Patients admitted to the PICU for more than three days were offered to participate in this study. Parents or legal guardians were asked to sign the consent form. Exclusion criteria included PICU admission of less than 72 hours and known gastrointestinal disease prior to admission that could affect intestinal transit, such as abdominal surgery. This study was carried out from December 2014 to February 2015 (Figure 1).

Hydrogen monitor Gastroplus ${ }^{\circledR}$ (Isomed Pharma ${ }^{\circledR}$, SL Madrid, Spain) was used for $\mathrm{eH}_{2}$ testing. This monitor measures expired hydrogen $\left(\mathrm{eH}_{2}\right)$ in parts per million (ppm), but it does not measure methane. Before each test, monitor calibration was performed according to the instructions of the manufacturer using a standard gas sample containing 92$100 \mathrm{ppm} \mathrm{eH}_{2}$. Lactulose was used as a substrate. The oral cavity was cleaned with chlorhexidine $(0.05 \%)$ before the test in every patient.

An adaptation system that allowed $\mathrm{eH}_{2}$ measurement in patients with invasive mechanical ventilation was designed. A connection with a valve attached to a collecting bag was inserted at the end of the expiratory limb of the breathing circuit (Figure 2).

The end of the expiratory limb was the safest place for implementation because it does not alter the patient's ventilation and it does not interfere with ventilator measurements. The valve was opened at the time of measuring and several patient exhalations were collected to fill the collecting bag. Once the bag was closed, the air was removed by a $50 \mathrm{~mL}$ polyethylene syringe connected to a valve system to prevent losses and contamination. Then, the air was blown into

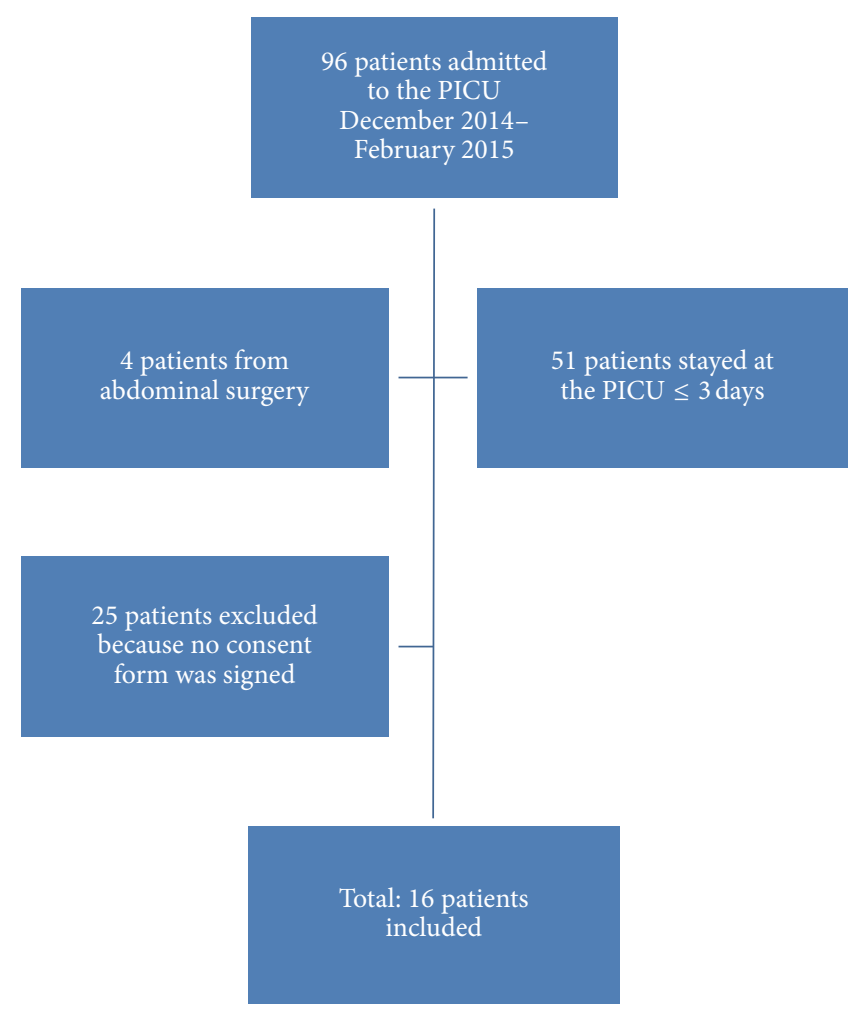

FIGURE 1: Patient recruitment flow chart.



FIGURE 2: Adaptation system to allow $\mathrm{eH}_{2}$ measurement in patients with invasive mechanical ventilation.

the breath hydrogen monitor and $\mathrm{eH}_{2}$ measurement was recorded.

This adapted system was tested first in 6 healthy volunteers who were breathing spontaneously. They were asked to breathe normally, without forcing expiration, through the ventilator tubes with the inspiratory limb closed. $\mathrm{eH}_{2}$ measurements were obtained at baseline and 30, 60, 90, 120, 180, 240, and 300 minutes after oral lactulose intake. All of them showed normal $\mathrm{eH}_{2}$ measurements with peaks around 90-180 minutes after lactulose intake.

For those noncooperating children, we followed our protocol with nasobuccal masks as usual at the gastroenterology ward: our clinical practice includes a nasobuccal mask where children breathe directly connected to the hydrogen monitor. Parents press masks a bit over children faces to avoid leaks.

Lactulose- $\mathrm{eH}_{2}$ tests were made a few days after PICU admission and in children under no antibiotic treatment. Postsurgical children had only one cefazolin dose just before 
surgery starting so effect over the test was considered almost zero. We obtained baseline $\mathrm{eH}_{2}$ measurements from those patients included in the study before we administered $0.5 \mathrm{~g} / \mathrm{kg}$ of oral lactulose (maximum dose $10 \mathrm{~g}$ ) diluted to $10 \%$ water by the nasogastric tube. After that, $\mathrm{eH}_{2}$ measurements were performed every 30 minutes for the first 2 hours and every 15 minutes for the following 4 hours or until a peak rise in breath hydrogen by $10 \mathrm{ppm}$ above baseline was reached. Patients without an $\mathrm{eH}_{2}$ peak after 6 hours were considered non-hydrogen producers.

Collected data included age, sex, weight, history of constipation (defined as hard stools and/or a frequency of less than 1 bowel movement every 48-72 hours), diagnosis, reason for admission, illness severity scores at admission (Pediatric Risk of Mortality III [PRISM III], Pediatric Index of Mortality 2 [PIM2], and Pediatric Logistic Organ Dysfunction [PELOD]) [17-19], and length of PICU stay. Constipation was defined as an absence of bowel movements for more than 3 days based on criteria used in critically ill adult and pediatric patients $[3,4,6,20,21]$. A daily record of bowel movements, doses of intravenous sedative, analgesic, muscle relaxant, and inotropic drugs, and the need for mechanical ventilation was kept throughout the patient's PICU admission (up to 7 days). The starting day of enteral nutrition as well as the number of episodes of vomiting and the presence of abdominal distension were also recorded.

SPSS 21.0 software package (IBM SPSS Statistics, Chicago) was used for data analysis. Absence of normality was assured with the Kolmogorov-Smirnov test. Continuous variables are expressed as medians (interquartile range, IQR) and categorical variables as percentages. Mann-Whitney $U$ test and Fisher exact test were used for comparisons between continuous and categorical variables, respectively. Statistical significance was taken as a $p$ value of less than 0.05 .

\section{Results}

Sixteen patients (37.5\% boys) were included in this study. The median age was 19 (5-86.5) months and median weight was $7.2(5.2-18.7) \mathrm{kg}$ with a median length of stay of 15 (3.7-25.7) days. Constipation prior to admission was reported in $37.5 \%$ of patients. The most frequent cause of admission was postoperative cardiac surgery (13 patients: $81.3 \%$ ). Other causes were respiratory failure, neurologic disease, and neurosurgery (1 patient each: $6.3 \%)$. The median scores on clinical severity scales were PRISM III 10.0 (1.5-30.8), PIM2 2 (0.3-16), and PELOD 9.2 (0.1-19.6).

Five patients $(31.2 \%)$ were breathing spontaneously. Two of them were excluded from the study: one vomited after lactulose intake and the other one had breakfast 90 minutes after lactulose administration. In the other three patients, the test had to be interrupted before any results were obtained due to the anxiety that the expiration through the mask for $\mathrm{eH}_{2}$ measurement was causing.

Eleven patients with invasive mechanical ventilation were studied and $\mathrm{eH}_{2}$ test was performed successfully in all of them. The median age was 16 months (4-90 months) and median weight was $7.1 \mathrm{~kg}(5.1-19 \mathrm{~kg})$. The most frequent cause of admission was postoperative cardiac surgery (8 patients:
$72.3 \%)$. Other causes were respiratory failure, neurologic disease, and neurosurgery (1 patient each: $9 \%$ ). The median scores of clinical severity scales were PRISM III 1.10 (1.5-33), PIM2 7.6 (0.8-17.8), and PELOD 16.2 (0.1-20.8). Constipation prior to admission was reported by parents in three patients (27.3\%).

The lactulose- $\mathrm{eH}_{2}$ test was performed after a median of 5 days (2-9 days) of PICU admission. Three patients were fasted at the time of the test, while the rest of them were on continuous enteral nutrition through a nasogastric or transpyloric tube. The median time to start intestinal movements was 4 days (2-5 days). Six patients (54.5\%) presented constipation during PICU stay.

Seven patients $(63.3 \%)$ did not show an $\mathrm{eH}_{2}$ peak during the 6-hour study after lactulose intake. In the other four patients, median time from lactulose intake to a $10 \mathrm{ppm}$ $\mathrm{eH}_{2}$ peak was $130 \mathrm{~min}$ (78.7-278.7 min) (normal time in healthy children is $65 \pm 15.3$ minutes) $[12,22]$.

There were no differences in any of the variables between children with and without an $\mathrm{eH}_{2}$ peak (Table 1).

Children with an $\mathrm{eH}_{2}$ peak had intestinal movements earlier than those without one [6.5 (1.5-38.5) versus 44 (2472 ) hours], although no significant differences were found $(p=0.545)$.

There were no side effects from lactulose intake or from the modified technique to obtain $\mathrm{eH}_{2}$ from the ventilator tubes.

\section{Discussion}

Our study is the first to analyze the possibility of using $\mathrm{eH}_{2}$ breath test to measure GCTT in critically ill children. Lactulose- $\mathrm{eH}_{2}$ test is based on the fact that this substrate is a nonabsorbable disaccharide that is fermented by colonic bacteria. The hydrogen produced by the bacteria is absorbed through the wall of the small or large intestine, or both. The hydrogen-containing blood travels to the lungs where the hydrogen is released and exhaled in the breath where it can be measured [13]. $\mathrm{eH}_{2}$ measurements are made every 10-15 minutes for a period between 180 and 240 minutes. GCTT is the time between the administration of lactulose and the rise of at least $10 \mathrm{ppm}$ of $\mathrm{eH}_{2}$ from baseline in two followed determinations. The test has a better reproducibility for solid lactulose, but administration is more complicated in critically ill patients, so a liquid solution was used in our study.

Several studies found a good correlation between prolonged GCTT measured with lactulose- $\mathrm{eH}_{2}$ test in constipated children [13, 22] while other studies did not [23]. The main limitation of this test is the variability of results in healthy volunteers and the lower reproducibility of the test with the liquid substrate $[10,13]$. Other researchers have also faced difficulties in interpreting $\mathrm{eH}_{2}$ breath test [24].

Our study shows that lactulose- $\mathrm{eH}_{2}$ test is not feasible in critically ill children with spontaneous breathing. This test requires cooperation that is almost impossible to obtain due to their clinical situation: either they are unable to perform forced active expiration or this generates anxiety. Stress and 
TABLE 1: Comparison between patients with positive and negative expired $\mathrm{H}_{2}$ peak.

\begin{tabular}{|c|c|c|c|}
\hline Variable & $\mathrm{No} \mathrm{eH}_{2}$ peak, $n=7(63.6 \%)$ & $\mathrm{eH}_{2}$ peak, $n=4(36.4 \%)$ & $p$ value \\
\hline \multicolumn{4}{|l|}{ Demographic data at admission } \\
\hline Age (months) & $22(4-102)$ & $13.5(5-61)$ & 0.545 \\
\hline Weight (kg) & $6.2(5.1-26)$ & $7,2(4.5-7.8)$ & 1 \\
\hline Males & $2(28.5 \%)$ & $1(25 \%)$ & 0.721 \\
\hline Previously constipated & $2(28.5 \%)$ & $1(25 \%)$ & 0.721 \\
\hline Cardiac surgery & $6(85.7 \%)$ & $2(50 \%)$ & 0.279 \\
\hline \multicolumn{4}{|l|}{ Clinical severity scores } \\
\hline PRISM III (\%) & $24.5(1.5-53.4)$ & $5.4(1.2-10.5)$ & 0.061 \\
\hline PIM2 (\%) & $4.9(0.8-64.4)$ & $11.2(2-16)$ & 1 \\
\hline PELOD (\%) & $16.2(0.1-20.8)$ & $0.7(0.1-12.5)$ & 0.236 \\
\hline Vasoconstrictors (epinephrine/norepinephrine) & $1(14.2 \%)$ & $1(25 \%)$ & 0.618 \\
\hline \multicolumn{4}{|l|}{ Sedation/analgesia } \\
\hline Midazolam $\left(\mathrm{mcg} \cdot \mathrm{kg}^{-1} \cdot \mathrm{min}^{-1}\right)$ & $2(0-3)$ & $0.35(0-0.9)$ & 0.194 \\
\hline Fentanyl $\left(\mathrm{mcg} \cdot \mathrm{kg}^{-1} \cdot \mathrm{h}^{-1}\right)$ & $2(1-3)$ & $0.6(0-1)$ & 0.194 \\
\hline Muscle relaxants (vecuronium) & $2(28.5 \%)$ & $0(0 \%)$ & 0.382 \\
\hline \multicolumn{4}{|l|}{ Gastrointestinal } \\
\hline Fasting & $2(28.5 \%)$ & $1(25 \%)$ & 0.721 \\
\hline Vomiting & $1(14.2 \%)$ & $0(0 \%)$ & 0.636 \\
\hline Constipated patients & $3(42.8 \%)$ & $3(75 \%)$ & 0.348 \\
\hline Length of PICU stay (days) & $15(11-36)$ & $22(6.2-44.5)$ & 1 \\
\hline Time from admission to lactulose- $\mathrm{eH}_{2}$ test (days) & $4(1-9)$ & $7.5(2.25-16.5)$ & 0.242 \\
\hline
\end{tabular}

$\mathrm{H}_{2}$ : hydrogen; PRISM III: Pediatric Risk of Mortality III; PIM2: Pediatric Index of Mortality 2; PELOD: Pediatric Logistic Organ Dysfunction; PICU: Pediatric Intensive Care Unit.

Continuous variables are expressed as medians (interquartile range) and categorical variables as absolute number (percentage).

hyperventilation in 3 out of 5 patients made it impossible to perform the test correctly.

In mechanically ventilated adults, $\mathrm{eH}_{2}$ measurement is connected directly to the endotracheal tube [25]. However, this can greatly increase respiratory dead space and produce significant hypoventilation in children. Therefore, it is necessary to collect the air in a special collecting bag, so a Ttube with a control valve was inserted in the expiratory limb of the breathing circuit (Figure 2) to reduce handling of the endotracheal tube. This allowed an adequate minute volume with no impact on ventilation parameters. The test in healthy volunteers showed that this method is suitable for collecting samples for testing.

A $10 \mathrm{ppm} \mathrm{eH}_{2}$ increase was absent in most of our patients and, in patients in whom it was present, no correlation was found between GCTT and patient's defecation rhythm or any other clinical or treatment variables.

GCTT could only be measured in four patients (36.4\%), and although it was longer for constipated children [22], no correlation was found between the GCTT and the time to stooling or any other nutritional complication, suggesting that the test has no clinical usefulness in the critically ill child.

The failure to detect $\mathrm{eH}_{2}$ levels in a high percentage of patients could be due to several factors [24]. First, these children could be methane producers instead of hydrogen producers. Methane was not measured in our study. The percentage of methane production in the general population varies between 5 and $34 \%[10,24]$. However, this percentage is much lower than the failure to detect $\mathrm{eH}_{2}$ observed in our study (64\%). Another possible factor might be a very slow GCTT (of more than 6 hours). Some drugs such as inotropes or opioids [26] slow GCTT, but no significant differences in doses of inotropes or opioids were found between children with positive and negative $\mathrm{eH}_{2}$ test in our study. There was no correlation with a delay in intestinal movements either. Moreover, lactulose administration directly into the stomach through a nasogastric tube could justify slight acceleration but not a delay in GCTT.

Therefore, according to our results, lactulose- $\mathrm{eH}_{2}$ test does not seem to be useful to measure GCTT in children with mechanical ventilation, although the designed amendment is useful for collecting breath samples. Moreover, given the high number of measurements that must be obtained to determine GCTT over 6 or more hours, this test would determine a significant burden of work for the nursing staff.

There are other devices for measuring GCTT in constipated children as ${ }^{13} \mathrm{C}$-lactose, colonic radioscintigraphy, colonic manometry capsule motility, or radiopaque markers. However, most of these techniques cannot be performed in critically ill patients due to invasiveness, the need for patient mobilization, the lack of reference values, the need for endoscopy, or the difficulty of managing radiotracers $[10,27-$ 30].

Our study has certain limitations due to the low number of patients, as the study was terminated prematurely due to the absence of positive results. Nevertheless, the number of 
subjects was sufficient to meet the first objective of the study. More studies about this should be done to clarify this item.

\section{Conclusions}

Although the designed adaption is useful for collecting breath samples, lactulose- $\mathrm{eH}_{2}$ test seems to be of little utility for measuring GCTT in critically ill children because of the high amount of work and difficulties associated with it.

\section{Competing Interests}

The authors declare that they have no competing interests.

\section{Authors' Contributions}

J. López and C. Sánchez contributed equally to this study.

\section{Acknowledgments}

This study was performed with a grant support from Carlos III Health Institute (PI10/1933) and Promotion and the European Regional Development Fund (ERDF), Ref. RD12/0026. Red SAMID-RETICS is funded by the PN I+D+I 20082011 (Spain), ISCIII-Sub-Directorate General for Research Assessment and Promotion, and the European Regional Development Fund (ERDF), Ref. RD12/0026.

\section{References}

[1] A. Ukleja, "Altered GI motility in critically Ill patients: current understanding of pathophysiology, clinical impact, and diagnostic approach," Nutrition in Clinical Practice, vol. 25, no. 1, pp. 16-25, 2010.

[2] J. López-Herce, "Gastrointestinal complications in critically ill patients: what differs between adults and children?" Current Opinion in Clinical Nutrition and Metabolic Care, vol. 12, no. 2, pp. 180-185, 2009.

[3] A. R. Blaser, M. L. N. G. Malbrain, J. Starkopf et al., "Gastrointestinal function in intensive care patients: terminology, definitions and management. Recommendations of the ESICM Working Group on Abdominal Problems," Intensive Care Medicine, vol. 38, no. 3, pp. 384-394, 2012.

[4] A. P. Nassar Jr., F. M. Q. da Silva, and R. de Cleva, "Constipation in intensive care unit: incidence and risk factors," Journal of Critical Care, vol. 24, no. 4, pp. 630.e9-630.e12, 2009.

[5] T. Nguyen, A.-J. Frenette, C. Johanson et al., "Impaired gastrointestinal transit and its associated morbidity in the intensive care unit," Journal of Critical Care, vol. 28, no. 4, pp. 537.e11-537.e17, 2013.

[6] J. López, M. Botrán, A. García et al., "Constipation in the critically ill child: frequency and related factors," Journal of Pediatrics, vol. 167, no. 4, pp. 857-861.e1, 2015.

[7] G. Nind, W.-H. Chen, R. Protheroe et al., "Mechanisms of gastroesophageal reflux in critically ill mechanically ventilated patients," Gastroenterology, vol. 128, no. 3, pp. 600-606, 2005.

[8] J. Landzinski, T. H. Kiser, D. N. Fish, P. E. Wischmeyer, and R. MacLaren, "Gastric motility function in critically ill patients tolerant vs intolerant to gastric nutrition," Journal of Parenteral and Enteral Nutrition, vol. 32, no. 1, pp. 45-50, 2008.
[9] E. Husebye, "The patterns of small bowel motility: physiology and implications in organic disease and functional disorders," Neurogastroenterology \& Motility, vol. 11, no. 3, pp. 141-161, 1999.

[10] E. Scarpellini, L. Abenavoli, C. Balsano, M. Gabrielli, F. Luzza, and J. Tack, "Breath tests for the assessment of the orocecal transit time," European Review for Medical and Pharmacological Sciences, vol. 17, supplement 2, pp. 39-44, 2013.

[11] S. V. Rana and A. Malik, "Hydrogen breath tests in gastrointestinal diseases," Indian Journal of Clinical Biochemistry, vol. 29, no. 4, pp. 398-405, 2014.

[12] P. Vajro, G. Silano, D. Longo, A. Staiano, and A. Fontanella, "Orocoecal transit time in healthy and constipated children," Acta Paediatrica Scandinavica, vol. 77, no. 4, pp. 583-586, 1988.

[13] A. Gasbarrini, G. R. Corazza, M. Montalto, and G. Gasbarrini, "Methodology and indications of $\mathrm{H}$ 2-breath testing in gastrointestinal diseases: final statements from the Ist Rome consensus conference," Alimentary Pharmacology and Therapeutics, vol. 29, no. 1, pp. 32-33, 2009.

[14] G. Metz, M. A. Gassull, A. R. Leeds, L. M. Blendis, and D. J. Jenkins, "A simple method of measuring breath hydrogen in carbohydrate malabsorption by end expiratory sampling," Clinical Science and Molecular Medicine, vol. 50, no. 3, pp. 237240, 1976.

[15] R.-J. M. Brummer, U. Armbrecht, I. Bosaeus, G. Dotevall, and R. W. Stockbruegger, "The hydrogen $\left(\mathrm{H}_{2}\right)$ breath test: sampling methods and the influence of dietary fibre on fasting level," Scandinavian Journal of Gastroenterology, vol. 20, no. 8, pp. 1007-1013, 1985.

[16] W. S. Lee, G. P. Davidson, D. J. Moore, and R. N. Butler, "Analysis of the breath hydrogen test for carbohydrate malabsorption: validation of a pocket-sized breath test analyser," Journal of Paediatrics and Child Health, vol. 36, no. 4, pp. 340-342, 2000.

[17] M. M. Pollack, K. M. Patel, and U. E. Ruttimann, "PRISM III: an updated pediatric risk of mortality score," Critical Care Medicine, vol. 24, no. 5, pp. 743-752, 1996.

[18] A. Slater, F. Shann, and G. Pearson, "PIM2: a revised version of the paediatric index of mortality," Intensive Care Medicine, vol. 29, no. 2, pp. 278-285, 2003.

[19] S. Leteurtre, A. Martinot, A. Duhamel et al., "Validation of the paediatric logistic organ dysfunction (PELOD) score: prospective, observational, multicentre study," Lancet, vol. 362, no. 9379, pp. 192-197, 2003.

[20] J. C. Montejo, "Enteral nutrition-related gastrointestinal complications in critically ill patients: a multicenter study," Critical Care Medicine, vol. 27, no. 8, pp. 1447-1453, 1999.

[21] S. M. Mostafa, S. Bhandari, G. Ritchie, N. Gratton, and R. Westone, "Constipation and its implications in the critically ill patient," British Journal of Anaesthesia, vol. 91, no. 6, pp. 815-819, 2003.

[22] A. C. F. Soares, H. M. Lederman, U. Fagundes-Neto, and M. B. De Morais, "Breath hydrogen test after a bean meal demonstrates delayed oro-cecal transit time in children with chronic constipation," Journal of Pediatric Gastroenterology and Nutrition, vol. 41, no. 2, pp. 221-224, 2005.

[23] M. A. Benninga, H. A. Büller, G. N. J. Tytgat, L. M. A. Akkermans, P. M. Bossuyt, and J. A. J. M. Taminiau, "Colonic transit time in constipated children: does pediatric slow-transit constipation exist?" Journal of Pediatric Gastroenterology and Nutrition, vol. 23, no. 3, pp. 241-251, 1996.

[24] V. Ruzsanyi, P. Heinz-Erian, A. Entenmann et al., "Diagnosing lactose malabsorption in children: difficulties in interpreting 
hydrogen breath test results," Journal of Breath Research, vol. 10, no. 1, Article ID 016015, 2016.

[25] N. Q. Nguyen, M. P. Ng, M. Chapman, R. J. Fraser, and R. H. Holloway, "The impact of admission diagnosis on gastric emptying in critically ill patients," Critical Care, vol. 11, no. 1, article R16, 2007.

[26] N. G. Levein, S. E. Thörn, and M. Wattwil, "Dopamine delays gastric emptying and prolongs orocaecal transit time in volunteers," European Journal of Anaesthesiology, vol. 16, no. 4, pp. 246-250, 1999.

[27] M. Pizzoferrato, F. Del Zompo, F. Mangiola et al., "Specific 13C functional pathways as diagnostic targets in gastroenterology breath-tests: tricks for a correct interpretation," European review for medical and pharmacological sciences, vol. 17, pp. 45-50, 2013.

[28] S. M. Mugie, M. E. Perez, R. Burgers et al., "Colonic manometry and colonic scintigraphy as a diagnostic tool for children with severe constipation," Journal of Pediatric Gastroenterology and Nutrition, vol. 57, no. 5, pp. 598-602, 2013.

[29] A. C. F. Soares, S. Tahan, and M. B. De Morais, "Effects of conventional treatment of chronic functional constipation on total and segmental colonic and orocecal transit times," Jornal de Pediatria, vol. 85, no. 4, pp. 322-328, 2009.

[30] J. R. Infante, J. I. Rayo, J. Serrano, M. L. Dominguez, L. Garcia, and M. Moreno, "Functional fecal retention visualized by 111InDTPA colon transit scintigraphy," Clinical Nuclear Medicine, vol. 40, no. 6, pp. e331-e333, 2015. 


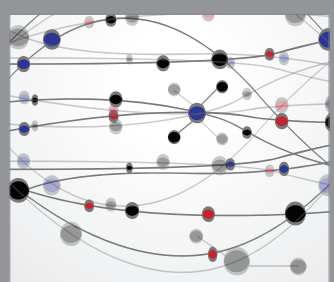

The Scientific World Journal
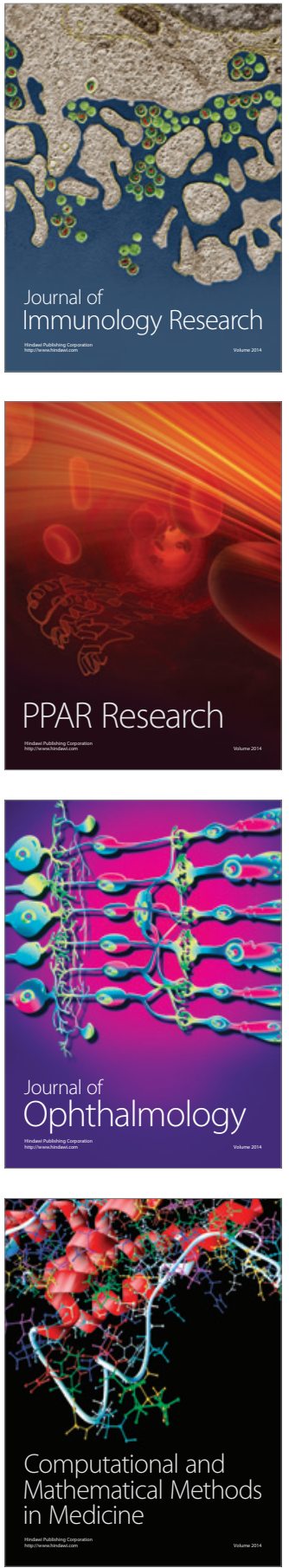

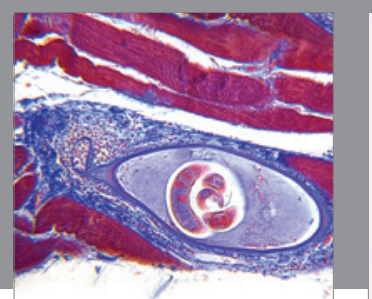

Gastroenterology Research and Practice


Disease Markers

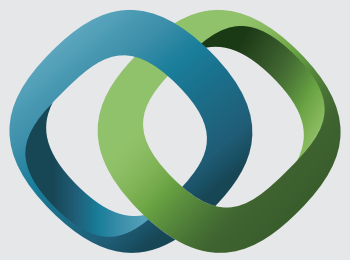

\section{Hindawi}

Submit your manuscripts at

https://www.hindawi.com
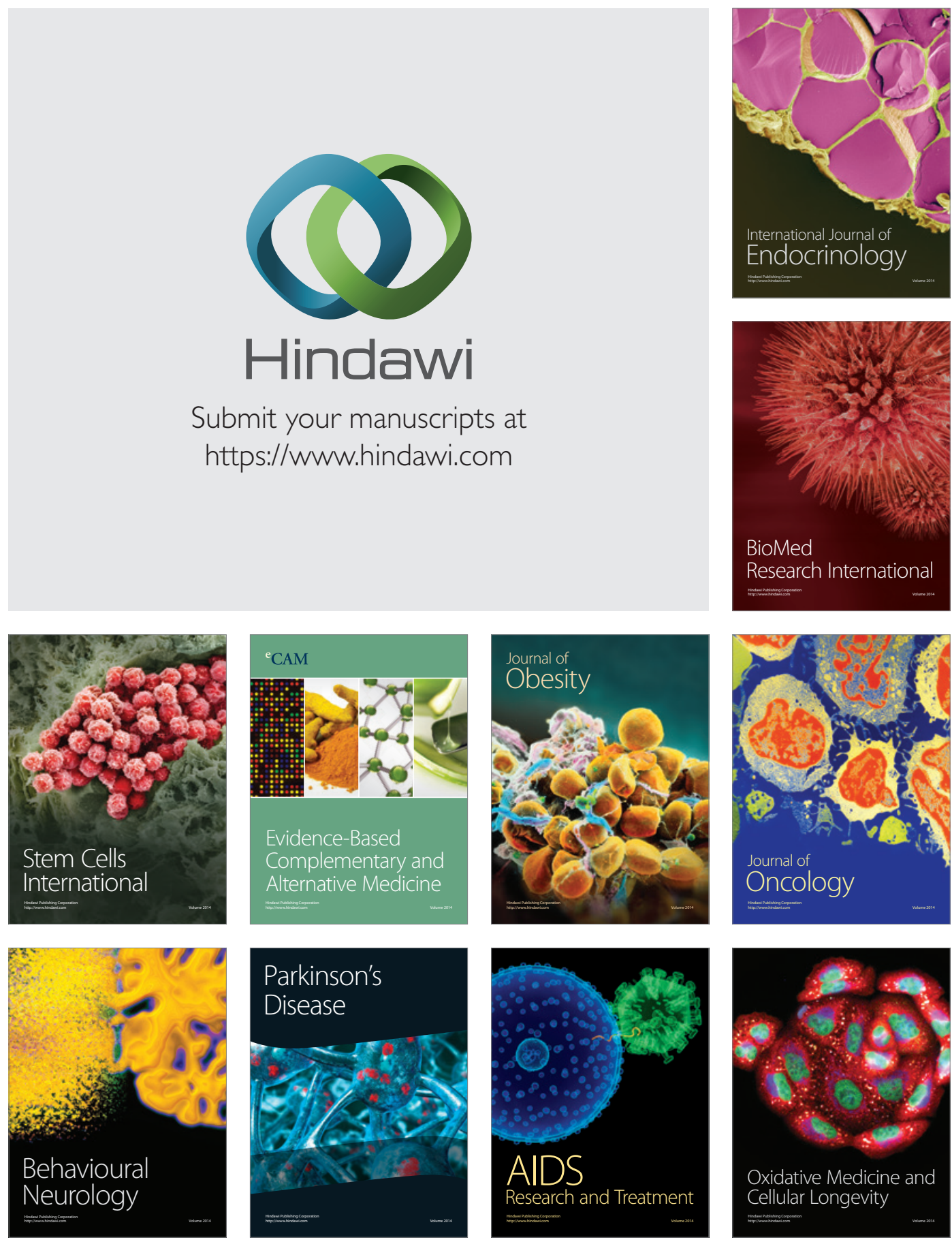